\title{
Considerações sobre o tema "Saúde dos Trabalhado- res da Saúde" e breve apresentação
}

\author{
Considerations on the theme "Health workers' health" and a \\ short presentation
} que passa a ser reconhecido socialmente no Brasil sem que, todavia, tenha despertado de forma significativa o olhar dos atores sociais envolvidos e das diversas instâncias de gestão dos serviços.

De um lado, o Estado defende a necessidade de concentrar esforços para a "humanização da assistência”: alguns programas, como a Saúde da Família e a Saúde mental, representam esse esforço público de melhorar a assistência. De outro, a "humanização" tem sido habitualmente entendida de forma restrita, sem contemplar devidamente a influência do ambiente e das relações de trabalho na qualidade dos cuidados prestados aos usuários dos serviços.

Como os agravos à STS podem constituir-se em fator de impedimento para o funcionamento dos programas e serviços para promover a saúde da população, conhecê-los e compreender sua relação com o trabalho de atenção e cuidados é algo fundamental.

Seu surgimento pode estar associado a vários fatores: a natureza do trabalho e os riscos presentes nas situações de trabalho, as condições de execução do trabalho, os modos de organização e de gestão dos serviços e a implementação de programas públicos.

Os estudos contidos neste número abordam aspectos desta problemática em alguns segmentos de trabalhadores da saúde.

Lorenzi e Oliveira investigam a prevalência de tuberculose em enfermeiros, utilizando base de dados do Conselho Regional de Enfermagem de São Paulo. Com base em dados do EPI-TB (banco de dados do Programa de Controle de Tuberculose de São Paulo), os autores mostram que enfermeiros pertencentes à faixa etária de 20 a 29 anos apresentam risco maior de tuberculose-doença do que o da população de referência (paulistana) para o ano de 2004.

Xavier et al. abordam a magnitude do fenômeno do assédio moral no setor saúde do Rio de Janeiro a partir de uma pesquisa realizada em 2001. Os autores caracterizam agressores, agredidos, as reações das vítimas e fatores contribuintes para sua ocorrência. Diante do grande número de trabalhadores vítimas de assédio e da "invisibilidade do problema", sugerem novas pesquisas a fim de tornar-se visível o fenômeno e de fomentar medidas de controle nos ambientes de trabalho.

Silva e Athaíde analisam a atividade de trabalhadores de unidade básica pertencente ao Programa de Saúde da Família. A despeito das lacunas existentes nas prescrições do programa, os autores mostram o papel dos trabalhadores na redefinição da "ação pública” a fim de assegurar maior eficácia na atenção à população. 
Ramminger e Brito propõem reflexão sobre a relação entre saúde e trabalho de servidores públicos que atuam em um Centro de Atenção Psicossocial (CAPS). Abordam a problemática da saúde dos trabalhadores da saúde mental, buscando colocar a experiência dos trabalhadores no centro da análise da relação entre saúde e trabalho. Mostram que os trabalhadores sofrem diante dos impedimentos para atender os pacientes e diante das próprias exigências da Reforma Psiquiátrica.

Da leitura destes textos, um aspecto essencial merece destaque tanto do ponto de vista prático, quanto científico. O trabalho dos servidores da saúde tem papel central no funcionamento e na implementação dos programas públicos (JEANNOT, G. Les métiers flous. Travail et action publique. Toulouse: Octarès Éditions, 2005.), isto é, surge como enigma para ser revelado pela comunidade científica, que se preocupa com a situação dos trabalhadores que, para promover a saúde da população, colocam em risco sua própria saúde (JACKSON, M.; BARCELOS, M. A. Entre a qualidade na promoção à saúde e a manutenção da própria saúde: as contradições do trabalho das agentes comunitárias de saúde do Posto de Saúde do Boehmerwaldt - Programa de Saúde da Família, Joinville. Relatório de pesquisa. Fundacentro/SC, Florianópolis, 1999). Compreendê-lo é passo fundamental para melhorar os processos de trabalho em saúde, que surgem como garantia da "humanização da atenção" (SOUZA, M. S.; MOREIRA M. C. N. A temática da humanização na saúde: alguns apontamentos para debate. Interface, Botucatu, v. 12, n. 25, p. 327-38, 2008).

Mais dois artigos e uma comunicação breve formam este número. Vasconcelos et al., ao estudar o trabalho dos coletores de lixo de Belo Horizonte, mostram as estratégias desenvolvidas pelos trabalhadores para serem mais eficazes e para diminuírem o risco de acidentes. Costa e Menegon analisam a introdução da Saúde e Segurança do Trabalho em duas pequenas e em uma média empresa no Estado de São Paulo. Oliveira et al. realizam estudos com o objetivo de conhecer a taxa de efeito booster (usado na triagem tuberculínica) em uma população de profissionais de saúde de um hospital universitário de Mato Grosso do Sul.

Este número da RBSO apresenta-se, assim, em novo formato, contendo trabalhos do dossiê sobre o tema "Saúde dos Trabalhadores da Saúde", além de artigos submetidos ao fluxo contínuo da revista, conforme sugestão do Conselho Editorial da Revista.

Esperamos, dessa forma, continuar a contribuir com o avanço do campo da Saúde e Segurança do Trabalho.

Boa leitura! 